\section{Um die Stammzelltherapie ist es still \\ geworden - und das ist gut so}

\author{
Der Hype um regenerative Therapien bei Herzerkran- \\ kungen sei in letzter Zeit deutlich abgeflacht. „Und das \\ ist eine gute Nachricht", konstatierte Prof. Andreas \\ Zeiher vom Universitätsklinikum Frankfurt am Main.
}

W enn ein Thema nicht ständig in den Medien präsent sei, könne man Studien realisieren, die darauf abzielen, tatsächlich einen Beweis für den Nutzen einer Therapie zu erbringen und zwar für den Patienten, meint Prof. Zeiher. Mittlerweile sind vier große Outcome-Studien zu regenerativen Therapien in der Herz-Kreislauf-Medizin angelaufen.

\section{BAMI-Studie mit 3.000 Teilnehmer}

Eine davon ist die BAMI-Studie („Bonemarrow-derived mononuclear cell on all cause mortality in Acute Myocardial Infarction"), eine randomisierte Phase3-Studie, bei der europaweit etwa 3.000 Patienten mit akutem Myokardinfarkt rekrutiert werden sollen. Untersucht wird der Effekt einer intrakoronaren Infusion von mononuklearen Knochenmarksstammzellen drei bis sechs Tage nach der primären PCI auf die Gesamtsterblichkeit von Patienten, die sich von der Reperfusion nicht erholt haben. 480 Patienten seien bereits eingeschlossen, berichtete Zeiher, der selbst an der Studie mitwirkt.
Der akute Infarkt stellt seiner Ansicht nach einen guten Ansatzpunkt für eine Stammzelltherapie dar. Denn das Ziel hier sei einfach, eine Ausweitung des Ventrikels zu verhindern.

\section{Herausforderung Herzinsuffizienz}

Schwieriger hingegen gestaltet sich eine entsprechende Behandlung der chronischen Herzinsuffizienz. In diesen Fällen geht es darum, das linksventrikuläre Remodeling umzukehren. Allein mit vom Patienten gewonnenen Stammzellen komme man hier nicht weiter, meint Zeiher. Als Lösungsansätze diskutiert werden daher eine induzierte Differenzierung von Progenitorzellen aus Knochenmark, Blut, Skelettmuskulatur usw. durch Genveränderungen oder mithilfe einer Inkubation spezieller Molekülcocktails sowie eine Vorbehandlung der Zielregion, beispielsweise mit Stoßwellen. Beim ESC-Kongress im August 2016 sollen erste Ergebnisse einer großen Studie vorgestellt werden, die auf dem Ansatz der C-CURE-Studie basiert, berichtete Zeiher. In C-CURE („Cardiopoietic stem Cell therapy in heart failURE“) sind mesenchymale Stammzellen einem kardiogenen Cocktail ausgesetzt und die dadurch erzeugten kardiopoetischen Stammzellen Patienten mit ischämisch bedingter Herzinsuffizienz injiziert worden. Nach sechs Monaten hatte sich die linksventrikuläre Ejektionsfraktion der Patienten mit der Zelltherapie im Vergleich zu den Kontrollpatienten signifikant verbessert.

\section{Konzept wiederholter Zellinfusion}

Eine weitere Studie, an der Zeiher ebenfalls beteiligt ist, ist die REPEAT-Studie. In dieser im Dezember 2013 gestarteten Studie wird an 670 Herzinsuffizienz-Patienten überprüft, ob eine wiederholte Infusion von Knochenmarksstammzellen die Gesamtsterblichkeit sowie die Rate an Rehospitalisierungen und kardialem Tod verringern kann. Denn eines sei klar, so Zeiher, bei der regenerativen Therapie der chronischen Herzinsuffizienz sei es mit einer einmaligen Anwendung sicherlich nicht getan. Eine komplette Regeneration werde jedoch nie möglich sein.

Veronika Schlimpert

\section{Biologische Schrittmacher - "a very long way to go"}

Stammzellen statt Device - die Vision eines „biologischen Schrittmachers" wird wohl so schnell nicht Realität werden; denn die ideale Zelle für ein „Cardiac Repair" ist noch in weiter Ferne.

\footnotetext{
uch wenn der Hype um die Stammzellen etwas abgeklungen ist, bleibt es doch eine faszinierende Vision, untergegangenes Herzgewebe durch neue Zellen zu ersetzen. Ein Herzzellersatz könnte nicht nur für herzinsuffiziente Patienten einen therapeutischen Durchbruch
}

bedeuten. Vielmehr ist auch ein „biologischer Schrittmacher" denkbar, der das herkömmliche Device ersetzt.

\section{Hoffnungsvoll stimmende Daten}

Die Forschungsaktivitäten im Bereich der zellulären Elektrophysiologie kon-

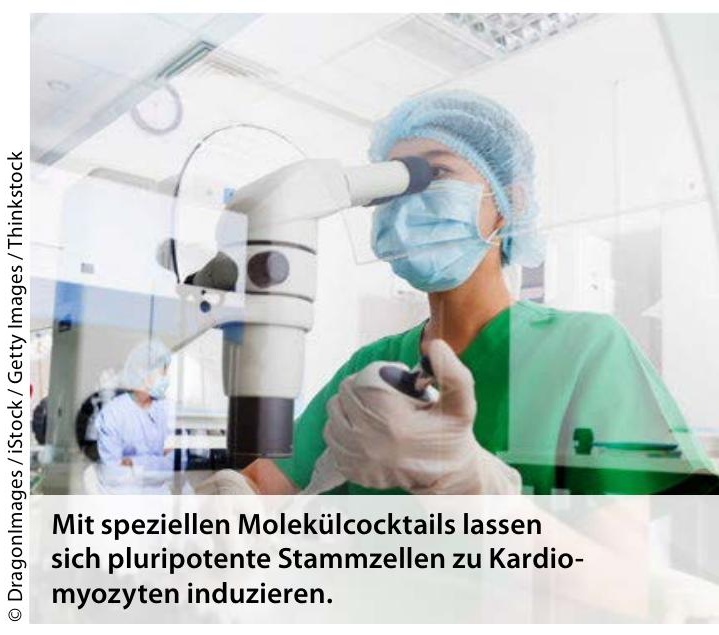

